\title{
The attitudes of European consumers toward innovation in bread; interest of the consumers toward selected quality attributes.
}

\author{
J.L. LAMBERT ${ }^{(1)}$, A. LE-BAIL ${ }^{(1)}$, R. ZUNIGA ${ }^{(1)}$, I. VAN-HAESENDONCK ${ }^{(2)}$, E. VAN- \\ ZEVEREN $^{(2)}$, M.C. ROSELL ${ }^{(3)}$, C. COLLAR $^{(3)}$, D. CURIC ${ }^{(4)}$, K. GALIC $^{(4)}$, M. SIKORA $^{(5)}$ \\ ${ }^{(1)}$ ENITIAA - GEPEA, UMR CNRS 6144, BP 82225, F-44322 NANTES Cedex 3, FRANCE \\ (2) PURACOR-PURATOS Group, Industrialaan 25, B-1702 Groot-Bijgaarden, BELGIUM \\ (3) IATA-CSIC, Cereal Group, POBox 73. Burjasot 46100. Valencia, SPAIN \\ (4) ZAGREB UNIVERSITY - PBF, 10000 Zagreb, CROATIA \\ ${ }^{(5)}$ University of Agriculture, Balicka 122, 30-149 Krakow, POLAND
}

Corresponding author : lebail@enitiaa-nantes.fr

\section{Summarized}

The present survey is integrated in the European project entitled EU-FRESHBAKE. This three years project started in October 2006. It aims at developing innovative processes and innovative formulations for the Bake Off technology taking into consideration, energy demand of the process, nutrition parameters and overall quality of the bread.

To help and to advise the project on the expectations of the European consumers toward innovation, a consumer survey has been carried out taking into consideration 1050 consumers from 5 countries (Belgium, Croatia, Spain, France and Poland). The global objectives are (i) to better understand the attitudes of the European innovations in bread and (ii) to understand the main determinants of it. Globally the key points that arose from the survey were the environmental concern and the concern regarding health; these two aspects seem to steer the attitudes of the consumer. Basically, two categories of consumers were observed; (i) frequent (daily) buyers with a focus on quality and pleasure and (ii) less frequent buyers (once a week) with a more pronounced interest in nutrition and energy (process). The first group was named the crust group and the second one the crumb group. The crumb family seems to be the one that is the most interested in the outcomes of the EU-FRESHBAKE project. This group is concerned by nutrtition quality and would prefer a bread which has been done with a less energy demanding process. The "crust" group is schematically less interested in the nutrition, in the shelf life and in the energy demand of the process used to preprare the bread. The results from this survey should be handled with care due to the relative small size of the sample and to the fact that the average age of the sample was rather young.

\section{INTRODUCTION}

The presented survey is integrated in a research project funded by the European union within the $6^{\text {th }}$ framework program. This project concerns the bake off technology (BOT) which consists in producing breads from industrial frozen or non frozen industrial products.

Bread and baked cereals goods and many other specialties are at the base of the pyramid of nutrition (Figure 1). The European market is under the pressure of the demand of European 
consumer, willing to have a large variety of breads including eventually ethnic products, health promoting products, non allergenic products (i.e. gluten free bread) with a high level of "freshness" ("freshly beaked" like) and organoleptic qualities. .

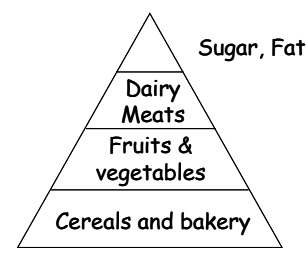

Figure 1

Scheme of the ratio of a diet (USDA, 2000) ( http://www.usda.gov/cnpp/DietGd.pdf )

Beside, the labour cost and the demand of the consumer for fresh bread resulted in the rapid growing of the BAKE OFF TECHNOLOGY (BOT) which consists in delivering bread, viennoiserie or others bakery products produced at an industrial scale to down town small "hot points". These hot points are in fact some baking shops with a minimally trained staff able to prepare any kind of product on demand using fermentation cabinet and oven. The market share of frozen bakery products seems little but is growing at a very high rate (more of less around 10\%/year).

One of the drawback of the BOT lies in that the processes used are energy demanding (double baking, freezing process, frozen storage ... are energy demanding). The partial baking process consists in doing a preliminary partial baking at the industry level followed by a final baking in the shop. Most of these partially baked breads are frozen. In final, such process results in almost twice more energy demand than a conventional direct baking. There is thus a challenge to reduce the energy demand of the processes of the BOT. The consumer may also expect a high quality in term of nutrition. Products from BOT are most of the time sold unpacked without any information on the nutrition facts. The second challenge is related to nutrition quality (i.e; glycaemic index, bioavailability of nutrient, ...) which may be improved by using specific processes and/or specific recipes. A third challenge is how these information should be brought to the knowledge of the consumer regarding nutrition, energy demand or anu other point of interest. Hidden behind these major objectives, innovative technologies, equipments and formulations may be developed.

Based on the foregoing reasons, the EU-FRESHBAKE project was started in 2006 for a period of three years to help the European Baking Industry. In order to conduct this project 12 European and non-European countries are involved (see Figure 2 and Table 1). Also 5 industrial Companies, 1 producing organic breads (BIOFOURNIL - France), 2 producing gluten free breads (BEZGLUTEN - Poland and SCHAER - Italy, 1 company producing baking ingredients (PURATOS - Belgium) and 1 company producing baking equipments (MIWE - Germany) are involved in this project. 


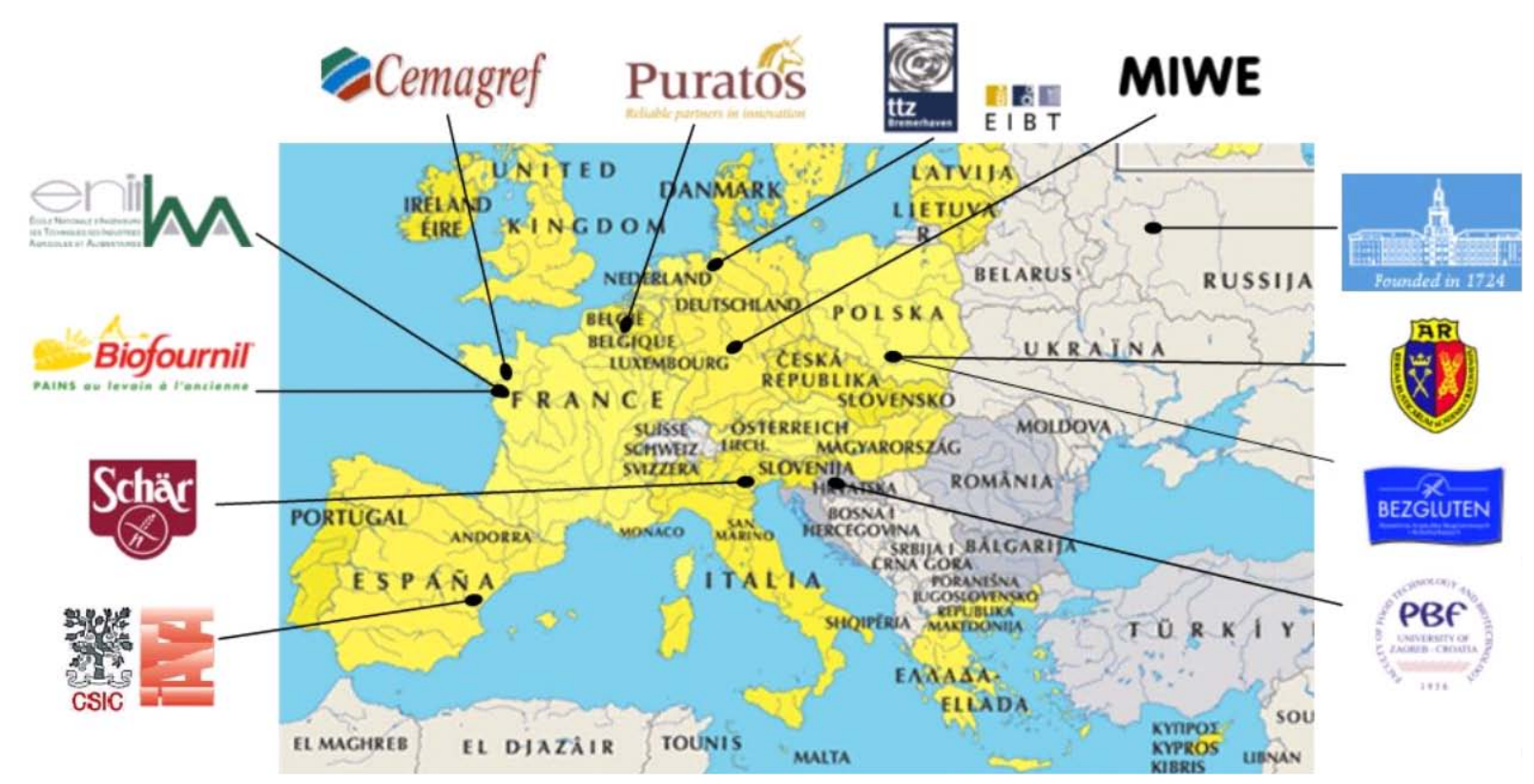

Figure 2

Overview of the partners involved in the EU-FRESHBAKE project

(http://eu-freshbake.eu/eufreshbake)

Table 1

Partners of the EU-FRESHBAKE project

\begin{tabular}{|l|l|l|}
\hline PARTICIPANT & COUNTRY & WEBSITES \\
\hline 1. ENITIAA - coordinator & FRANCE & www.enitiaa-nantes.fr \\
\hline 2. CEMAGREF & FRANCE & www.cemagref.fr \\
\hline 3. KRAKOW UNIVERSITY & POLAND & www.ar.krakow.pl \\
\hline 4. IATA-CSIC & SPAIN & www.iata.csic.es \\
\hline 5. ZAGREB UNIVERSITY & CROATIA & www.pbf.hr \\
\hline 6. TTZ-EIBT & GERMANY & www.ttz-bremerhaven.de \\
\hline 7. RUSSIAN ACADEMY of SCIENCE IBCP RAS & RUSSIA & www.ras.ru \\
\hline 8. MIWE - Industry & GERMANY & www.miwe.com \\
\hline 9. PURATOS - Industry & BELGIUM & www.puratos.com \\
\hline 10. BIOFOURNIL - Industry & FRANCE & www.biofournil.com \\
\hline 11. BEZGLUTEN - Industry & POLAND & www.bezgluten.pl \\
\hline 12. DR. SCHÄR - Industry & ITALY & www.schaer.com \\
\hline
\end{tabular}

This consumer survey has been designed in considering the energy demand, the organoleptic quality and the nutrition as main field of interest (keywords). The reduction of energy concerns obviously the producers and distributors of foods, whereas the consumers are centred more on the features of food. It is therefore likely that the consumers of bread who answer this objective positively are the citizens for which the environment and the ecology is an important value.

The improvements of the nutritional features and organoleptic are integrated to the social representations and to the systems of values of the consumers that determine their attitudes and their behaviours (Lambert, 1987, Fischler, 1990, Lahlou, 1998, Colt, 2002). The food is integrated to the general management of the wellbeing of a human. The pleasure provided by 
food and the risk in term of food safety can dominate according to the consumers. But the same individuals can alternate their expectations according to the circumstances (Raven, Colt, 2002).

The extension of the shelf life of bread is rather bound on economical considerations and on temporal and spatial constraints. The management of food shopping is closely related to the socio-economical category and may vary therefore according to the life styles (Colt, 2001,; Asher, 2005,; Lambert et al., 2005). Bread is a very specific food. The consumers may prefer to buy bread daily or based on its shelf life according to their preferences. The frequency of consumption of bread is also extremely uneven. There are people who never eat bread and others may consider bread as a main food.

The question of the information on the composition of bread and nutrition facts available for the consumers sends back to the types of relations between the suppliers (shop) and the purchasers (consumers). The suppliers can take advantage of a favourable balance of powers in the context of penury, when the offer is lower than the demand and the purchasers cannot be demanding. On the other hand, in the present European market which is saturated, the purchasers can have more influence on the transactions. Besides, in democratic societies where the ideology of the individual liberty is predominant, the consumers may not accept products without information or labelling. The sanitary risks bound to the food amplify the expectations of information in this domain (Lambert, 2005). The bread is also not an exception to these general tendencies.

The important place of bread in the history of food in Europe (Montanari, 1995,; Flandrin, Montanari, dir., 1996; Gruegel, Laurioux, dir., 2002) can bring however to wonder about the attitudes of the consumers toward bread. Bread is probably again a "cultural food" for a part of the European. However, many studies of sociology, anthropology and history applied to food (Fischler, 1990,; Rozin, 1996,; Giachetti, dir., 1996; Lambert, 1996, 2000) showed that the consumers that put a lot of emphasis on bread are maybe the consumers which mainly reject innovation and which are minimally attracted by innovations in food. This attitude that may be called "neophobia" can be even more important with regard to a cultural food like bread. Being given the "sacred character" in relation with its place in the evangel some consumer may even think that it has to remain an "untouchable" product!.

Bread covers a large number of concept viz., type, shape, colour, recipe (salty vs. sweet), composition and texture. It is likely that regional and social differences in habits and preferences are exacerbated through these different types of bread. Hence with the new technologies applied in the EU-FRESHBAKE project may have an impact on the quality attributes in the bread among selected countries in Europe.

Finally, if one assess the attitudes of the consumers with regard to the various propositions of this research program, one should not forget that the perception of food by the consumer is global. Several aspects are integrated by the consumer, including the price, the outlook of the product but also the production systems (i.e. in a bakery you can see the baker preparing the bread), the packaging and the labelling.

\section{METHODOLOGY AND DATA TREATMENT}

The survey has been carried out using a questionnaire, which was filled up during the interview. The face-to-face interview has been done with 1050 consumers in 5 different 
countries; Belgium - flemish county, Belgium - Wallon county, Croatia, Spain, France and Poland. These countries were selected to offer a span of European cultures. The survey has been done between October 2006 and March 2007. The scientists have led the investigation from the different research groups involved in the project. An excel file has been finally filled up gathering all the answers that were coded. The questionnaire has been designed on a collective approach keeping in mind selected objectives that were of interest for the EUFRESHBAKE project.

The concept of the questionnaire includes:

- practices of purchases

- practice of consumption

- psychological representation of bread

- degree of importance of bread in the diet

- interest and importance of nutrition

- interest about gluten free bread

- $\quad$ interest in the energy needed to produce a bread (environmental concern)

- degree of importance of the shelf life of bread

- degree of acceptance of "innovation" in bread

The awareness about "gluten free" bread questions were taken with respect to the fact that gluten free breads will be studied within the EU-FRESHBAKE project. Even though the gluten free market is small (linked to the non tolerance of the proteins contained in the bread celiac disease), there might be an interest for the consumer about such type of product. In addition to these "oriented" questions, a choice among selected pictures of bread was included. These pictures showed breads with different structure, colour and cellular (crumb) structure. Typically 4 to 5 breads were presented but the picture was sometimes different from one country to the other one.

At this stage of the research project, the objective of the investigation is especially to tag the main attitudes and try to understand the main determinants of it. The aim is more qualitative and is not to provide evaluations of the reactions of the European facing the considered innovations. The sample cannot be considered as strictly representative of the European population nor the 5 countries. It has been constituted with a heterogeneous sociodemographic composition in such a way that the main interesting social groups for the analysis have a sufficient number ( $>100$ ). The sample population selected may not be perfect for example the popular classes (workers) were less than $3 \%$ of the interviewed and the intermediate professions - technicians, middle managers were less than $7 \%$. On the other hand, the students and those that have a formation superior to the final exam were over represented (about 25\% of the sample). When these sub parameters were integrated, one can also conclude that this survey permits an observation more deepened within the social groups that may be more sensitive.

\section{RESULTS}

The answers to the improvements and innovation considered in the EU-FRESHBAKE project have been crossed with most variables of the questionnaire to mark the determining factors. To assess the magnitude of the differences between proportions, we used the hypergeometric law. The statistical test was expressed in number of standard deviation of a normal law (Morineau, 1984). Therefore, when the value-test is higher than 2 in absolute value, the difference can be considered as significant at a 5\% level. The tables provided at follow will 
give the detail of these results classified by decreasing order of value of the test, knowing that only the modes of the significant variables have been kept.

\section{A strong interest with regard to the improvement of the nutrition quality, but without any change in the price of the bread.}

The most interested consumers in nutritional improvements (Depending on the degree of education, gluten may appear as a positive or negative ingredient. In fact, some people were not aware about the meaning of gluten and by presenting a "gluten free" products makes that the gluten appears all at once as a negative ingredients (if it is removed, then may be it is some suspicious compound). The positive attitude of consumers with a higher degree of education towards gluten free breads is therefore not surprising. On the other hand, it is important to mention that most consumers ( $3 / 4$ of the interviewed) are not willing to pay $10 \%$ more for such "gluten free" products. Their interest for the information on the composition and nutrition facts is logical and is associated to the existence of packing. Their preferences for the features of bread are rather corresponding the consumers of the "crumb group" (as defined in the introduction) or of sweet bread (see Figure 2) and bread doesn't have a particular value among food (a food as the other). This level of nutritional awareness as well as this type of preference seems more frequent in the countries of Northern Europe where the potential health benefit in foods prevails over the hedonism, opposite to what one can observe in the Latin countries. This aspect is also associated to preoccupations with regard to the environment.

Table 2) are the individuals concerned with their health and their out look. These consumers, with a higher degree of education have also a better background in nutrition and some more precise ideas about the "gluten" concept. Gluten, the proteins contained in wheat flour represents an interesting subject. Depending on the degree of education, gluten may appear as a positive or negative ingredient. In fact, some people were not aware about the meaning of gluten and by presenting a "gluten free" products makes that the gluten appears all at once as a negative ingredients (if it is removed, then may be it is some suspicious compound). The positive attitude of consumers with a higher degree of education towards gluten free breads is therefore not surprising. On the other hand, it is important to mention that most consumers (3/4 of the interviewed) are not willing to pay $10 \%$ more for such "gluten free" products. Their interest for the information on the composition and nutrition facts is logical and is associated to the existence of packing. Their preferences for the features of bread are rather corresponding the consumers of the "crumb group” (as defined in the introduction) or of sweet bread (see Figure 2) and bread doesn't have a particular value among food (a food as the other). This level of nutritional awareness as well as this type of preference seems more frequent in the countries of Northern Europe where the potential health benefit in foods prevails over the hedonism, opposite to what one can observe in the Latin countries. This aspect is also associated to preoccupations with regard to the environment.

Table 2

Table presenting the most interested consumers by nutritional improvements of bread. Test values (number of standard deviation vs. normal law) larger than 2 indicate that the gap can be considered as significant with a 5\% threshold. 


\begin{tabular}{|l|l|c|}
\hline Variables & Significant modality & Test value \\
\hline Interest toward nutrition improvment & nutrition yes & 37.81 \\
\hline Gluten knowledge & Modality n ${ }^{\circ}$ & 6.88 \\
\hline I want to remain slim, to prevent weight intake & Fully agree & 6.55 \\
\hline Attitude toward gluten free bread & gluten yes & 6.30 \\
\hline Acceptable over coast in case of nutrition improvment & $<10 \%$ more expansive & 6.19 \\
\hline I take care of being in good health & Fully agree & 4.91 \\
\hline Interest toward composition - bread recipe & Very important & 4.88 \\
\hline Prix pour amélioration nutritionnelle & 10 to 20 \% more expansive & 4.30 \\
\hline Caractéristiques du pain 1 & Freshly baked - packed & 3.95 \\
\hline Interest toward the energy demand & Interest in energy reduction & 3.64 \\
\hline Interest toward environement & Very important & 3.52 \\
\hline Aimez-vous le pain 1 & Very staled & 3.51 \\
\hline Habitat & 50 à 200000 hab & 3.35 \\
\hline Pays & Belgium - Flemish & 3.24 \\
\hline Pain accompagnement plats déjeuner et dîner & Never & 3.12 \\
\hline Bread: a food like any other one & Fully agree & 3.08 \\
\hline Country & Spain & 3.00 \\
\hline The recipe of a bread can contain milk & Milk = yes & 2.99 \\
\hline I have a freezer at home & Freezer = yes & 2.73 \\
\hline Prefered slice of bread & Prefered slice = \#3 & 2.60 \\
\hline Do you like bread without crust & without crust = yes & 2.55 \\
\hline Country & Poland & 2.53 \\
\hline Accepted over price if nutrition quality is improved & $<50$ \% more expansive & 2.52 \\
\hline Industrial foods are less tasty & Fully agree & 2.41 \\
\hline
\end{tabular}

The interest towards gluten free bread (Table 3) appeared as quite significant and of interest for all consumers. Due to the fact that the question about the interest toward gluten free breads was not just asked to people suffering from gluten allergy, the rather high percentage of people interested by such products (52\%) is probably linked to neophilia consumers (79\% among them) that are interested by "new" products and innovative products. These consumers are also relatively open minded and are accepting ingredients that have nothing to do with a conventional recipe of bread (i.e. olives...). These consumers are mostly concerned by their health; nevertheless, they don't forget the pleasure of the food, which remains for them an important issue. The organoleptic properties of gluten free bread will therefore be an important challenge for these consumers.

Table 3

The most interested consumers by gluten free bread.

Test values (number of standard deviation vs. normal law) larger than 2 indicate that the gap can be considered as significant with a 5\% threshold. 


\begin{tabular}{|l|l|c|}
\hline Variables & Significant modality & Test value \\
\hline Attitude toward gluten free bread & Gluten = yes (interest) & 37.79 \\
\hline Interest toward nutrition improvment & Yes I am interested & 6.30 \\
\hline Attitude toward new products & I want to try & 5.97 \\
\hline The recipe of a bread can contain olive, fruits, ... & yes I agree & 3.94 \\
\hline Interest toward environement & Very important & 3.80 \\
\hline Gluten knowledge ? & I know gluten & 3.79 \\
\hline Prefered slice of bread ? & Prefered slice $=\# 1$ & 3.79 \\
\hline I want to remain slim, to prevent weight intake & Fully agree & 3.73 \\
\hline Interest toward composition - bread recipe & Very important & 3.69 \\
\hline I take care of being in good health & Fully agree & 3.67 \\
\hline Eating is one of the great pleasure of life & Fully agree & 3.60 \\
\hline Country & Poland & 3.08 \\
\hline Age & 30 to 44 years old & 2.46 \\
\hline
\end{tabular}

\section{"Green" consumers, sceptical toward the food industry and interested in the reduction of energy consumption.}

It is not surprising that the interest for the reduction of the energy consumption (Table 4) is supported especially by "green" consumers concerned with the environment. Around half of them were concerned with their health. Without being extremely "neophobia" consumers, they appear distrustful with regard to the foods produced by the industry. They are therefore globally interested by the information on the bread composition. They especially eat sandwiches and can be interested by a prolonged shelf life. In summary, the sample populations interviewed were matching with the objectives of the EU-FRESHBAKE project. Nevertheless, their negative perception of industrial products has to be taken into account as well as the fact that half of these consumers will not accept any price increase. They would even find acceptable that bread would be cheaper..

\section{Table 4}

The most interested by the reduction of the energy consumption.

Test values (number of standard deviation vs. normal law) larger than 2 indicate that the gap can be considered as significant with a $5 \%$ threshold.

\begin{tabular}{|l|l|c|}
\hline Variables & Significant modality & Test value \\
\hline Interest toward environement & Very important & 9.07 \\
\hline Interest toward composition - bread recipe & Very important & 5.92 \\
\hline I take care of being in good health & Fully agree & 5.84 \\
\hline Indutrial foods are good for the health & Fully agree & 5.49 \\
\hline Country & Spain & 5.28 \\
\hline Interest for a bread with a long shel life & long shelf life = yes & 4.89 \\
\hline Price of the bread that demands less energy & 10 to 20 \% more expansive & 4.84 \\
\hline Industrial foods are less tasty & Fully agree & 4.34 \\
\hline Bread: a food like any other one & Fully agree & 3.99 \\
\hline Interest toward nutrition improvment & Yes & 3.64 \\
\hline I want to remain slim, to prevent weight intake & Fully agree & 3.42 \\
\hline Bread to prepare sandwich & Every day & 3.00 \\
\hline Emplyoment & Retired & 2.90 \\
\hline Gluten knowledge & Gluten not known & 2.70 \\
\hline Opinion versus bread with a long shelf life & long shelf life is possible & 2.66 \\
\hline Age & 65 years old and more & 2.65 \\
\hline Importance of the place of production of bread ? & Place of production = yes & 2.53 \\
\hline Do you like the bread \#1 ? & Very staled & 2.37 \\
\hline
\end{tabular}




\section{A limited interest in the extension of shelf life.}

$75 \%$ of the people interviewed prefer bread when it is still hot and buy bread every day (daily basis) or several times a week. The interest for a long shelf life would then allow a reduction of the frequency of purchase. Most of the bread in the market are staling quite quickly, the majority of consumers think that an extension of the shelf life will not allow a better "freshness". Therefore, it is not surprising that the most significant modality describing the consumers which are the most interested by an extension of the shelf life (Table 5) are also the consumers that are confident for the feasibility of the prolonged shelf life. These consumers are represented among the $7 \%$ of the global sample that prefer the pre packed partially baked bread (see Figure 4).

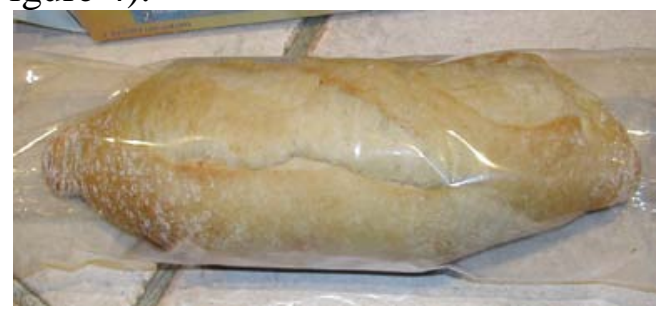

Figure 3

Example of a packed partially baked bread (French market)

The represented sample populationare "occasional" consumers of bread, taking it as a sandwich support. Also it was observed that mostly young men, who may be described as "functional" consumers, try to restrain the food shopping and the food preparation to a minimal level among other activities. Even though the frequency of purchases doesn't appear as significant, there might be a relatively weak relation with respect to the frequency of consumption. As these consumers rather prefer hot bread, they must be warm it. But they don't accept to spend more than $5 \mathrm{~min}$. for that and it is interesting to stress out that the micro wave oven is quite often their only domestic equipment for meal preparation. These consumers are more interested than the average by the reduction of energy, they constitute an interesting "target" for the EU-FRESHBAKE project, with one drawback concerning the fact that they do not take necessarily great care of their health.

\section{Table 5}

The most interested consumers by an elongation of the shelf life.

Test values (number of standard deviation vs. normal law) larger than 2 indicate that the gap can be considered as significant with a 5\% threshold. 


\begin{tabular}{|l|l|c|}
\hline Variables & Significant modality & Test value \\
\hline Opinion versus a bread with a long shelf life & A long shlf life is possible & 10.39 \\
\hline Country & Spain & 9.94 \\
\hline Accepted time of preparation at home & Baking should be less than 15min & 6.84 \\
\hline The "real bread", traditional bread & Bread \#1 & 5.50 \\
\hline Age & Less than 15 years old & 5.04 \\
\hline Interest toward the energy demand & Energy = yes & 4.89 \\
\hline Bread at breakfast used as toasts & Never & 4.75 \\
\hline Do you like bread \#1 & Warm bread & 4.25 \\
\hline Bread, a specific food with a holly - sacred value & Not agree at all & 4.21 \\
\hline Bread used to do sandwich & Every day & 4.19 \\
\hline Prefered slice of bread & Prefered slice = \#2 & 3.65 \\
\hline Sex & man & 3.18 \\
\hline Do you have a microwave oven at home & yes & 3.16 \\
\hline I take care of being in good health & Not really agree & 3.06 \\
\hline Preference toward crust texture & I don't care about bread texture & 2.79 \\
\hline Emplyoment & Student & 2.61 \\
\hline Level of professional education & Low & 2.53 \\
\hline I take care of being in good health & Not agree at all & 2.44 \\
\hline Accepted over price for a bread that is less energy demanding & 10 to 20\% more expansive & 2.44 \\
\hline Country & France & 2.35 \\
\hline
\end{tabular}

\section{A strong demand of information on the composition of bread.}

Eventhough information on the composition of bread is mandatory only for packed breads (regulatory constrain), almost 2/3 of the interviewed consider this aspect as very important or important. This attitude corresponds to a general tendency of the consumers that is stronger vis-à-vis food because of their sanitary consequences and of the food "identity" mentioned in the introduction; the most concerned consumers are within this survey (Table 6) who are interested in their health, particularly the oldest consumers, and the sample population that are attentive to their weight and their body outlook. Women, who generally are more concerned by these aspects are not very well represented in this survey. Also it is not astonishing to find consumers interested in the nutritional improvements within these categories of consumers.

On the other hand, it is surprising to mention that the most significant modality concerns the problem of environment. One can assume that these consumers are searching for some information on both the origin of the ingredients and the techniques of production. These consumers are may be "green" consumers with a higher level of expectation versus the average of the population towards their suppliers.

The demand of information is reinforced when the consumers are not confident towards their suppliers and when they have a negative representation of the food industry. These consumers are maybe the ones who think that the industrial food is less good for health and less tasty. An important ratio of the "green" consumers has this representation.

\section{Table 6}

The most interested consumers by information on the composition.

Test values (number of standard deviation vs. normal law) larger than 2 indicate that the gap can be considered as significant with a 5\% threshold. 


\begin{tabular}{|l|l|c|}
\hline Variables & Significant modality & Test value \\
\hline Interest toward environement & Very important & 8.85 \\
\hline I feel concerned by being in good health & Fully agree & 8.28 \\
\hline Industrial foods = good for the health & Fully agree & 6.22 \\
\hline I want to remain slim, to prevent weight intake & Fully agree & 6.12 \\
\hline Interest toward the energy demand to make a bread & Yes, I am concerned by energy & 5.92 \\
\hline Interest toward nutrion quatlity & Nutrition yes & 4.88 \\
\hline Employment & Retired & 3.98 \\
\hline Attitud vs. Gluten free breads & Gluten yes & 3.69 \\
\hline Industrial foods are less tasty & Fully agree & 3.51 \\
\hline Age & 45 to 64 years old & 3.50 \\
\hline Bread: a food like any other one & Fully agree & 3.20 \\
\hline Place of living - number of inhabitants & $>$ 200000 hab & 3.14 \\
\hline Slice of bread that is rejected & Rejected slice $=$ \# 2 & 3.06 \\
\hline Country & Belgium Wallon & 3.01 \\
\hline The recipe of a bread can contain sugar ... & Sweet = non interest & 2.90 \\
\hline Bread, a specific food with a holly - sacred value & Fully agree & 2.76 \\
\hline Do you like bread \#1 & Very staled & 2.74 \\
\hline Age & 65 years old amd more & 2.66 \\
\hline Gluten knowledge & Modality nº 1 & 2.51 \\
\hline Accepted time of preparation at home & Baking time $>15$ min & 2.51 \\
\hline
\end{tabular}

Globally, it is the system of values of the individuals, and especially the ecology - "green" sensitivity and the concern with regard to health, that seems to be the determining factors of the attitudes favourable to the "improvements" targeted within the EU-FRESHBAKE project. But the different centre of interests have strong relations. It is therefore applicable to do a synthesis of the attitudes declared by an analysis of multiple correspondences followed by a classification.

It is the importance of the interest with regard to information on the food composition that mostly distinguishes the classes. It reminds the relationship with the other preoccupations and can be considered therefore like a key indicator illustrating the general interest with regard to the objectives of the EU-FRESHBAKE project.

The class the most interested by the set of improvements considered within the research project "EU-FRESHBAKE" makes almost 18\% of the interviewed and is composed of relatively aged people (see Table 7). It is necessary to mention that people of this class are rather the "neophobia" having negative representations of the food industries. It is therefore likely that if the technologies that will be developed and the production - distribution processes give an industrial image, the expressed global interest will then be disrupted.

\section{Table 7}

Feature of the most interested classes by the set of the propositions of EU-FRESHBAKE Test values (number of standard deviation vs. normal law) larger than 2 indicate that the gap can be considered as significant with a $5 \%$ threshold. 


\begin{tabular}{|l|l|c|}
\hline Variables & Significant modality & Test value \\
\hline Interest toward composition - bread recipe & Very important & 28.52 \\
\hline Interest toward environement & Very important & 9.48 \\
\hline I feel concerned by being in good health & Fully agree & 8.43 \\
\hline Interest toward energy demand & Energy is important & 7.05 \\
\hline I want to remain slim, to prevent weight intake & Fully agree & 6.40 \\
\hline Industrial foods = good for the health & Fully agree & 5.98 \\
\hline Interest toward nutrion quatlity & Nutrition is important & 5.41 \\
\hline Attitude vs. Gluten free breads & Gluten yes (important) & 4.87 \\
\hline Industrial foods are less tasty & Fully agree & 3.80 \\
\hline Employment & Retired & 3.69 \\
\hline Bread: a food like any other one & Fully agree & 3.66 \\
\hline Age & 45 to 64 years old & 3.61 \\
\hline Place of living - number of inhabitants & $>$ 200,000 hab & 3.42 \\
\hline Bread, a specific food with a holly - sacred value & Fully agree & 3.05 \\
\hline Accepted time of preparation at home & Baking time more than 15 min & 2.96 \\
\hline Country & Belgium - Wallon & 2.77 \\
\hline Gluten knowledge & I know gluten & 2.66 \\
\hline Country & Croatia & 2.54 \\
\hline
\end{tabular}

The 2nd class, constituted by $1 / 3$ of the sample was found to be a little bit less interested, without meaningful socio-demographic features. To the difference of the previous class where the interviewees consider that bread is very important and holly food, the sample population of the second class does not distinguish the bread with the other food. In spite of a less obvious interest with respect to the previous class, the final degree of acceptance of the "new breads" by these individuals could therefore be an important factor.

\section{Habits of consumption and preferences with regard to bread not important on the expectations toward the EU-FRESHBAKE project.}

To complete this analysis, notably on the preferences with regard to the general types of bread as we evoked it in introduction, it seems necessary to mark and to differentiate here the main types of bread consumption. 


\section{Figure 4}

Typology of bread consumers observed within this survey

The behaviours of bread consumption are summarized in Figure 4, from an analysis of multiple correspondences. The frequency and the volume of consumption constitute the first factor of differentiation (horizontal axis 1). As for most present social practices, the axis 1 opposes the urban youngsters with a high degree of education to the old consumers that schematically live in rural area and who have a rather low degree of education. This opposition translates the fast evolutions between the generations, especially marked by the simultaneous development of the urbanization and the education which are associated with the new life styles. The decrease of frequency of bread consumption seems bound to this evolution.

The second factor distinguishes the individuals according to their preferences with regard to the types of bread and their main organoleptic features. The bread "experts" that one can essentially qualify as "traditional" old fashion consumers, are looking for old fashion breads made out of whole mill flour with a thick, colourful and crusty crust and a very honeycombed crumb. These consumers are in opposition to those that prefer the breads with a soft crumb, a pale crust, and schematically a bread that looks more like a sweet bread - Viennese breads type. These consumers are schematically representing the young population living in large cities. They are occasional consumers for whom bread has a relatively banal image. A significant part of the Polish and Belgian - Flemishes population for which bread looks more like a sort of viennoiserie bread are present in this group.

Among the "old style" daily consumers of bread, these consumers keep the image of bread as a basic food; "if I don't have any bread during a meal, something is clearly missing ". This opinion spilled especially in France. The open answer of some French people for "if I tell you bread, what do you think about? ", are as follows:

- $\quad$ "bread is an essential basic food, at the origin of the humanity "

- "bread is an element essential to the food, a basic food product"

- "bread feeds the humanity"

- "bread is a vital food, nearly indispensable"

- $\quad$ "it is the main in the meal; without bread, one doesn't eat "

- $\quad$ "I don't conceive any meal without bread ".

$-\quad \ldots$

Bread is therefore, for most of these consumers an important food, which is somehow a holly food. The biblical reference of the daily bread is arising here. Some French clearly express the following opinions:

- $\quad$ "Bread makes me think to the basis of the food, to the sacred and holly value, bread and wine like in the bible "

- "To make money means also to be paid to pay his daily bread, bread is the symbol of labor and of work; it is a symbol as much as a food" 
These consumers seem less favourable to the improvements of bread considered within the EU-FRESHBAKE project, but this "holly" and sacred representation of bread is not probably the only determinant. In answer to the introduction, bread would be therefore only "untouchable" for a restricted part of the population.

\section{Conclusion}

The obvious opposition between Northern Europe (Poland, Belgium-Flemish) and France, which appears on the axis 2 of the Figure 4, can depend on different consumption habits but can be bound also to the sociological compositions of the samples of the survey. For example, the positioning of Croatia on the factorial plan is certainly bound especially to the over representation of students in the sample.

Globally, it seems especially important to stress out that the declared interests by the interviewees with regard to the improvements proposed by the EU-FRESHBAKE project are bound very little to the preferences and consumption pattern of bread. They appear on the Figure 4 very close to the barycentre of the graph and are especially bound to the sociodemographic characteristics. Some complementary investigations will be however necessary to specify the targets of consumers interested by the EU-FRESHBAKE project, especially if the technologies that will be developed modify the organoleptic characteristic of breads, or are only compatible with some features. The hedonic tests of breads foreseen in the work program should be able to bring some answers to these important questions.

The introduction of this article reminded that the attitudes of the consumers with regard to the food innovations are generally uninviting. The "neophilia" attitude described $70 \%$ of the interviewees, which may be higher than the average of the European population; this group was identified when the answer to the question: "when you see some new food products, what to you rather tell to yourself ?" was "I want to try". This high ratio may be linked to the overrepresentation of "neophilia" groups such as young, urban, high level of education, students, high level employees and VIP, ...

One can also mention an important distrust rate vis-à-vis food industries. Also $3 / 4$ of the sample population consider that food products produced by the industry are less good and less tasty and around 60\% consider that they are less good for health. The evolution towards a more industrial production of bread might result in risks related to the distrust of a part of the population. This point must be integrated into the hedonic tests.

To conclude with the importance of this survey which indicates a rather positive perception of the targets of the EU-FRESHBAKE project, it seems important to remind that between the declared attitudes and the real behaviours of purchases, the gaps are often important, especially when the constraints of income and free time come in opposition to the representations and attitudes; the answers reserved on the levels of acceptable prices are the illustration of it.

\section{Acknowledgements}

This study (report, paper, workshop...) has been carried out with financial support from the Commission of the European Communities, FP6, Thematic Area "Food quality and safety", FOOD-2006-36302 EU-FRESH BAKE. It does not necessarily reflect its views and in no way anticipates the Commission's future policy in this area. 


\section{References}

Ascher F. 2005, Le mangeur hypermoderne, O. Jacob, Paris.

Corbeau J. P., Poulain J.P, 2002, Penser l'alimentation. Entre imaginaire et rationalité, Ed.

Privat, Toulouse.

Fischler C., 1990, L'homnivore. Odile Jacob, Paris.

Flandrin J.L., Montanari M., 1996, Histoire de l'alimentation. Fayard, Paris.

Giachetti I., 1996, Identités des mangeurs, images des aliments. Polytechnica, Paris,

Gruegel M.; Laurioux B., dir., 2002, Histoire et identité alimentaire en Europe, Hachette, paris.

Lahlou S., 1998, Penser manger. Alimentation et représentations sociales. Thèse de doctorat en psychologie sociale. PUF, Paris.

Lambert J.L., 1987, L'évolution des modèles de consommation alimentaire en France, Lavoisier Tec\&Doc, Paris.

Lambert J.L., 1996, Les mangeurs entre traditions et nouveautés : quelques spécificités du "marketing alimentaire, in : Giachetti I., dir., Identités des mangeurs, images des aliments. Polytechnica, Paris, pp.151-173.

Lambert J.L., 2000, La sensibilité à l'innovation et les déterminants de la consommation de nouveaux produits alimentaires, in NAFAS Pratique, Edition de Santé, Paris, vol.1, 2000, pp 7-13.

Lambert J.L., Batalha M., Sproesser R., Lago da Silva A., Lucchese T., 2005, As principais evolucoes dos comportamentos alimentares : o caso da França, in Revista de Nutriçao, Brazilian Journal of Nutrition, PUC Campinas, , $\mathbf{n}^{\circ} \mathbf{1 8}$, Tome 5, pp. 577-591.

Lambert J.L., 2005, Quelles informations pour les mangeurs ?, in Lambert J.L., Grujic, S, Grujic R., Food safety, information and education of consumers, Faculty of Technology, University of Banja Luka, pp. 7-36.

Montanari M., 1995.- La faim et l'abondance. Histoire de l'alimentation en Europe, Seuil, Paris.

Morineau A., 1984, Note sur la Caractérisation Statistique d'une Classe et les Valeurs-tests, Bulletin Technique Centre Statistique Informatique Appliquées., Vol 2, n 1-2, p 20-27.

Poulain J.P, 2001, Manger aujourd'hui, Privat, Toulouse.

Poulain J.P, 2002, Sociologies de l'alimentation, PUF, Paris.

Rozin P., 1996, Sociocultural influences on human food selection, in : Capaldi E., dir., Why we eat what we eat. The psychology of eating. British Library, USA, pp. 233-266. 